\title{
Crescimento e nodulação de Enterolobium contortisiliquum cultivado em solos de diferentes sistemas de uso no Sudoeste do Piauí
}

\author{
Antonieta Alexandrina de Jesus ${ }^{1}$, Elaine Martins da Costa ${ }^{2 *}$, Rafaela Simão Abrahão Nóbrega ${ }^{3}$, Larissa Castro Diógenes ${ }^{1}$, \\ Júlio Cesar Azevedo Nóbrega ${ }^{3}$ \\ 1 Universidade Federal do Piauí, Rod. Municipal Bom Jesus Km 01, Planalto Horizonte, CEP 64900-000, Bom Jesus, PI, Brasil \\ 2Universidade Federal de Mato Grosso do Sul, Zona Rural, CEP 79560-000, Chapadão do Sul, MS, Brasil \\ ${ }^{3}$ Universidade Federal do Recôncavo da Bahia, Centro de Ciências Agrárias, Ambientais e Biológicas, CEP 44380-000, Cruz das Almas BA, Brasil
}

\section{"Autor correspondente:}

elaine.costa@ufms.br

Termos para indexação:

Tamboril

Fixação de nitrogênio

Rhizobium

Index terms:

Tamboril

Nitrogen fixation

Rhizobium

Histórico do artigo:

Recebido em 30/05/2017

Aprovado em 10/11/2017

Publicado em 29/12/2017

doi: $10.4336 / 2017 . p f b .37 .92 .1460$

\begin{abstract}
Resumo - O objetivo deste trabalho foi avaliar o efeito de diferentes sistemas de uso dos solos do Sudoeste do Piauí no crescimento e nodulação natural de mudas de tamboril [Enterolobium contortisiliquum (Vell) Morong]. O experimento foi conduzido em viveiro da Universidade Federal do Piauí, em Bom Jesus, PI. O delineamento experimental foi inteiramente casualizado com dez repetições. Os tratamentos foram: quatro sistemas de uso do solo (duas áreas de mata nativa, uma área de pastagem e outra de agricultura). Aos 85 dias as mudas foram coletadas e avaliaram-se a altura $(\mathrm{H})$, o diâmetro do colo (DC), o número $(\mathrm{NN})$ e a matéria fresca de nódulos (MFN), as matérias secas da parte aérea (MSPA), das raízes (MSR) e total (MST), a relação entre matéria seca da parte aérea sobre a das raízes (MSPA/MSR), o índice de qualidade de Dickson (IQD) e o acúmulo de nitrogênio na parte aérea (ANPA). Ocorreu nodulação em todos os sistemas de uso dos solos. As mudas cultivadas em solos de áreas agrícolas e de pastagem apresentaram maior destaque quanto à nodulação, H, DC, MSPA e ANPA, do que as áreas de mata nativa.
\end{abstract}

\section{Growth and nodulation of Enterolobium contortisiliquum grown in soils under different soil use systems in southwest of Piaui State}

\begin{abstract}
The aim of this study was to evaluate the effect of soil use systems from Southwest of Piaui State, Brazil, in growth and natural nodulation of tamboril [Enterolobium contortisiliquum (Vell) Morong] seedlings. The experiment was conducted in greenhouse at the Federal University of Piaui, in Bom Jesus, PI. The experiment design was completely randomized with ten replications. Treatments were consisted of four soil use systems (two areas of native forest, one grassland and one agriculture area). Seedlings were collected 85 days after planting, when height $(\mathrm{H})$, collar diameter (CD), number of nodules (NN), nodule fresh matter (NFM), shoot (SDM), roots (RDM) and total dry matter (TDM), ratio of shoot and roots dry matter (SDM/TDR), Dickson quality index (DQI) and nitrogen accumulation in shoots (NAS) were evaluated. Nodulation occurred in all soil use systems. Seedlings grown under soils from agriculture and grassland areas showed higher performance on nodulation, $\mathrm{H}, \mathrm{CD}, \mathrm{SDM}$ and NAS than soils from native forest areas.
\end{abstract}

\section{Introdução}

A incorporação do nitrogênio $\left(\mathrm{N}_{2}\right)$ via fixação biológica $(\mathrm{FBN})$ nos diferentes ecossistemas naturais e/ou alterados representa uma alternativa viável para o aumento da produção vegetal, mantendo a sustentabilidade, além de proporcionar economia no uso de fertilizantes nitrogenados. Nesse sentido, a 
capacidade nodulífera das espécies de leguminosas arbóreas é importante sob o ponto de vista ecológico e econômico, sendo objetivo de muitos estudos (Souza et al., 2007; Silva et al., 2009; Jesus et al., 2014). Correlações positivas e significativas entre a nodulação e desenvolvimento de mudas de espécies arbóreas têm sido documentadas (Souza et al., 2007; Vieira \& Souza, 2011; Azad et al., 2013; Sousa et al., 2013).

Apesar do potencial de espécies leguminosas arbóreas nodulíferas na incorporação de $\mathrm{N}$ aos solos, diversos fatores, tais como atributos químicos e físicos do solo, condições climáticas, histórico de uso do solo e hospedeiro vegetal (Souza et al., 2007; Lima et al., 2009; Costa et al., 2014; Ferreira et al., 2015; Menezes et al., 2015), entre outros, influenciam a ocorrência e eficiência de populações nativas de bactérias fixadoras de nitrogênio nodulíferas em leguminosas (BFNNL), bem como o estabelecimento da simbiose e a eficiência do processo de FBN.

Estudos que avaliam a ocorrência e eficiência de populações de bactérias fixadoras de $\mathrm{N}_{2}$ que formam simbiose com leguminosas arbóreas podem fornecer informações importantes quanto à existência de estirpes nativas eficientes, que poderão ser isoladas e selecionadas para serem recomendadas como inoculantes, especialmente em ecossistemas tropicais, onde os solos, geralmente, apresentam elevadas temperaturas, $\mathrm{pH}$ ácido e baixa disponibilidade de nutrientes (Novais et al., 2007).

Para a análise da ocorrência e eficiência das populações nativas em fixar $\mathrm{N}_{2}$, a escolha da planta-isca é uma variável importante. A principal característica das plantas-iscas é a promiscuidade, ou seja, devem ser capazes de nodular com uma grande diversidade de BFNNL, para posterior seleção de estirpes com potencial de utilização como inoculantes em espécies leguminosas de interesse (Lima et al., 2009; Jaramillo et al., 2013; Castro et al., 2017).

Entre as leguminosas arbóreas tropicais, com capacidade para estabelecer simbiose eficiente com BFNNL, destaca-se o Enterolobium contortisiliquum (Vell) Morong. (Moreira et al., 2010; Sousa et al., 2013; Jesus et al., 2014), popularmente conhecido por tamboril, orelha-de-macaco, entre outras denominações. É uma leguminosa de rápido crescimento, com ampla utilidade (Lorenzi, 2008), além de ser tolerante a metais pesados (Rangel et al., 2014), o que a torna promissora para utilização em programas de reflorestamento e recuperação de áreas degradadas (Chaer et al., 2011).
Atualmente, já existe uma estirpe (BR 4406 Bradyrhizobium sp.) aprovada pelo Ministério da Agricultura Pecuária e Abastecimento (MAPA) para inoculação em tamboril (Brasil, 2011). No entanto, alguns estudos desenvolvidos recentemente verificaram baixa eficiência da inoculação dessa estirpe em mudas de tamboril (Sousa et al., 2013; Jesus et al., 2014). Além disso, esses dois estudos indicaram a ocorrência de populações nativas de bactérias diazotróficas, nos solos avaliados, capazes de nodular eficientemente o tamboril, promovendo acréscimos significativos no conteúdo de nitrogênio e melhoria da qualidade das mudas. Neste contexto, o presente trabalho teve por objetivo avaliar o crescimento e a nodulação natural de mudas de tamboril em solos de diferentes sistemas de uso na região Sudoeste do Piauí.

\section{Material e métodos}

O experimento foi conduzido de outubro de 2009 a janeiro de 2010 no viveiro para produção de mudas da Universidade Federal do Piauí (UFPI), Município de Bom Jesus (277 m de altitude, 0904'28"S, $\left.44^{\circ} 21^{\prime} 31^{\prime \prime} W\right)$, situado na região Sudoeste do Piauí. Durante o período experimental, foram registradas a umidade e a temperatura média interna no viveiro (Figura 1).

Os tratamentos foram constituídos por quatro solos

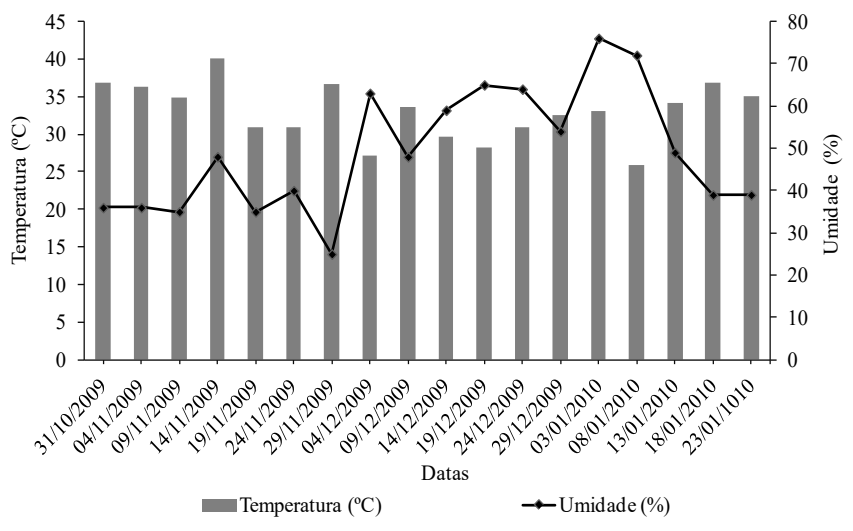

Figura 1. Umidade relativa e temperatura média interna no viveiro durante o período experimental.

procedentes de diferentes sistemas de uso (Tabela 1), sem histórico de utilização anterior de qualquer tipo de inoculante microbiano. Não existem também relatos de correção da acidez e adubação dos quatro solos descritos na tabela 1 . 
Tabela 1. Histórico e localização geográfica das áreas sob diferentes sistemas de uso no Sudoeste do Piauí.

\begin{tabular}{|c|c|c|c|}
\hline Uso do solo & Histórico das áreas & Classificação do solo & Coordenadas geográficas \\
\hline Mata nativa 1 & $\begin{array}{l}\text { Vegetação típica do bioma Caatinga, predominando arbustos ( } 2 \mathrm{~m} \\
\text { a } 5 \mathrm{~m} \text { ) que, em geral, perdem as folhas na estação seca. }\end{array}$ & Neossolo Litólico & $\begin{array}{l}09^{0} 07^{\prime} 9,15^{\prime \prime} \mathrm{S} \\
44^{0} 15^{\prime} 37,8^{\prime \prime} \mathrm{W}\end{array}$ \\
\hline Mata nativa 2 & $\begin{array}{l}\text { Vegetação de buritizal, onde predomina a palmeira Mauritia } \\
\text { flexuosa } \mathrm{L} \text {. }\end{array}$ & Não classificado & $\begin{array}{l}09^{\circ} 04^{\prime} 66,0^{\prime \prime} \mathrm{S} \\
44^{0} 21^{\prime} 64,00^{\prime \prime} \mathrm{W}\end{array}$ \\
\hline Pastagem & $\begin{array}{l}\text { Oito anos com plantio de pastagens (Brachiaria humudicola e } \\
\text { Andropogon sp.) e rodízio de animais. }\end{array}$ & Latossolo Amarelo & $\begin{array}{l}09^{0} 01 ' 24,00 ” \mathrm{~S} \\
44^{0} 18^{\prime} 13,8^{\prime \prime} \mathrm{W}\end{array}$ \\
\hline Agricultura & Vinte anos de rotação milho/feijão-caupi, plantio irrigado. & Latossolo Amarelo & $\begin{array}{l}09^{\circ} 04^{\prime} 27,0^{\prime \prime} \mathrm{S} \\
44^{0} 19^{\prime} 16^{\prime \prime} \mathrm{W}\end{array}$ \\
\hline
\end{tabular}

A partir do ponto georeferenciado (Tabela 1), foram coletadas, para cada solo, 12 amostras simples dispostas em círculos concêntricos de 3,0 e 6,0 m de raio, na profundidade de $0-0,20 \mathrm{~m}$. As amostras de cada uso do solo foram posteriormente misturadas para constituir a amostra composta dos pontos avaliados. Não foi realizada correção da acidez e adubação das amostras dos solos usadas como substratos de cultivo. Parte das amostras dos solos foi submetida a análises químicas (Tabela 2), de acordo com Claessen (1997).
As mudas foram produzidas em sacos plásticos, em 2,0 $\mathrm{kg}$ de solos. Antes da semeadura, realizou-se a quebra de dormência das sementes com ácido sulfúrico concentrado por $30 \mathrm{~min}$, seguida de lavagens em água corrente. Posteriormente, foi realizada a desinfestação em hipoclorito de sódio (10\%) por $1 \mathrm{~min}$, seguida de lavagens sucessivas com água destilada estéril. Foram semeadas três sementes por saco. Aos 16 dias após a semeadura (DAS) foi realizado o desbaste, deixando-se uma planta por parcela. A irrigação foi realizada diariamente, a fim de manter a umidade dos solos em torno de $60 \%$ da capacidade de campo.

Tabela 2. Caracterização química das amostras de solos em diferentes sistemas de uso, coletadas na camada de 0-20 m.

\begin{tabular}{|c|c|c|c|c|c|c|}
\hline \multirow[t]{2}{*}{ Uso do solo ${ }^{(1)}$} & $\mathrm{pH} \mathrm{H} \mathrm{H}_{2} \mathrm{O}$ & $\mathrm{P}$ & $\mathrm{K}^{+}$ & $\mathrm{Ca}^{2+}$ & $\mathrm{Mg}^{2+}$ & $\mathrm{Al}^{3+}$ \\
\hline & & \multicolumn{2}{|c|}{---- $\left(\mathrm{mg} \mathrm{dm}^{3}\right)$---- } & \multicolumn{3}{|c|}{---- $\left(\mathrm{cmol}_{\mathrm{c}} \mathrm{dm}^{-3}\right)$---- } \\
\hline MN1 & 5,35 & 2,20 & 21,10 & 0,70 & 0,40 & 0,50 \\
\hline MN2 & 5,50 & 2,90 & 25,20 & 0,60 & 0,30 & 1,20 \\
\hline PAS & 5,69 & 9,20 & 56,10 & 4,00 & 3,40 & 0,30 \\
\hline AGR & 5,61 & 24,70 & 41,00 & 1,20 & 1,00 & 0,40 \\
\hline \multirow[t]{2}{*}{ Uso do solo ${ }^{(1)}$} & $\mathrm{H}+\mathrm{Al}$ & SB & $\mathrm{t}$ & $\mathrm{T}$ & $\mathrm{V}$ & $\mathrm{m}$ \\
\hline & \multicolumn{4}{|c|}{--- $\left(\mathrm{cmol}_{\mathrm{c}} \mathrm{dm}^{-3}\right)$} & \multicolumn{2}{|c|}{---- (\%) ---- } \\
\hline MN1 & 1,90 & 1,15 & 1,65 & 3,05 & 37,70 & 30,30 \\
\hline MN2 & 1,70 & 0,96 & 2,16 & 2,66 & 36,09 & 55,55 \\
\hline PAS & 2,70 & 7,54 & 7,84 & 10,24 & 73,63 & 3,82 \\
\hline AGR & 1,70 & 2,30 & 2,70 & 4,00 & 57,50 & 14,80 \\
\hline
\end{tabular}

MN1 = vegetação típica do bioma Caatinga, predominando arbustos (2 a $5 \mathrm{~m}$ ) que, em geral, perdem as folhas na estação seca; MN2 = vegetação de buritizal, onde predomina a palmeira Mauritia flexuosa L.; PAS = oito anos com plantio de pastagens (Brachiaria humudicola e Andropogon sp.) e rodízio de animais. AGR = vinte anos de rotação milho/feijão-caupi, sob plantio irrigado. $\mathrm{pH} \mathrm{H}_{2} \mathrm{O}=\mathrm{pH}$ em água; $\mathrm{SB}=$ soma de bases; $\mathrm{t}$ e $\mathrm{T}$ = capacidade de troca catiônica efetiva e potencial, respectivamente; $\mathrm{V}=$ saturação por bases; $\mathrm{m}=$ saturação por alumínio.

O crescimento das mudas foi acompanhado periodicamente (a cada 17 dias), sendo medida a altura (H), com a utilização de régua graduada $(0,1 \mathrm{~mm})$, e o diâmetro do colo (DC), com auxílio de um paquímetro $(0,01 \mathrm{~mm})$ totalizando cinco avaliações $(17,34,51,68$ e 85 dias após a semeadura). 
Aos 85 dias após a semeadura, as plantas foram coletadas para avaliação dos seguintes parâmetros: número de nódulos (NN), matéria fresca de nódulos (MFN), matéria seca da parte aérea (MSPA), das raízes (MSR) e total (MST), relação entre a massa seca da parte aérea e da raízes (MSPA/MSR), acúmulo de nitrogênio na parte aérea (ANPA) e índice de qualidade de Dickson (IQD).

Para determinação da MSPA e MSR, a parte aérea e as raízes foram pesadas separadamente, colocadas em sacos de papel e postas pra secar em estufa com circulação de ar forçada a $60{ }^{\circ} \mathrm{C}$ até atingir massa constante. O ANPA foi calculado multiplicando-se o peso da MSPA (g) pelo teor de $\mathrm{N}$ na parte aérea $(\%) / 100$. O teor de $\mathrm{N}$ na parte aérea foi determinado pelo método semi-microkjedahl. O IQD foi determinado segundo Dickson et al. (1960), em que: $\mathrm{IQD}=\operatorname{MST}(\mathrm{g}) /[(\mathrm{H}(\mathrm{cm}) / \mathrm{DC}(\mathrm{mm})+\mathrm{MSR}(\mathrm{g}) /$ $\operatorname{MSPA}(\mathrm{g})]$.

O delineamento experimental utilizado foi inteiramente casualizado, com quatro tratamentos e 10 repetições, totalizando 40 parcelas. Os dados foram submetidos à análise de variância, usando o sistema de análise estatística SISVAR, versão 5.2 (Ferreira, 2011). As médias dos tratamentos foram comparadas pelo teste de Tukey, a 5\% de probabilidade. Foram estimados os coeficientes de correlação de Pearson entre as variáveis avaliadas, ao nível de 1 e $5 \%$ de probabilidade. Os dados de NN e MFN foram transformados pela raiz quadrada de $\mathrm{Y}+0,5$.

\section{Resultados}

Os valores médios de altura $(\mathrm{H})$ das mudas diferiram significativamente entre os sistemas de uso do solo em todas as épocas de avaliação, enquanto os valores médios de diâmetro do colo (DC) diferiram significativamente somente nas três últimas avaliações $(51,68$ e 85 dias após a semeadura - DAS) (Figura 2).

Os solos sob agricultura e pastagem proporcionaram valores médios de $\mathrm{H}$ e DC semelhantes entre si e significativamente superiores aos obtidos nos solos sob MN1 (mata nativa com vegetação típica do bioma Caatinga) e MN2 (mata nativa com vegetação de buritizal) para as avaliações realizadas aos 51 e 68 dias após a semeadura das mudas (Figura 2). Na avaliação realizada aos $85 \mathrm{DAS}$, os sistemas de uso agricultura (AGR) e pastagem (PAS) também proporcionaram valores médios de $\mathrm{H}$ significativamente superiores ao demais (Figura 2).
Houve efeito significativo dos sistemas de uso dos solos sobre todas as variáveis avaliadas aos 85 DAS (Figuras 2, 3 e 4). Em todos os sistemas de uso dos solos houve nodulação (Figura 3 ). Os maiores valores médios de número de nódulos $(\mathrm{NN})$ e matéria fresca de nódulos (MFN) foram obtidos nos solos sob PAS e AGR, os quais diferiram significativamente dos demais solos (Figuras 3a e 3b). Os solos sob MN1 e MN2 promoveram NN e MFN semelhantes entre si (Figuras 3a e 3b). Os valores médios de MFN variaram de 0,027 a 0,794 g planta $^{-1}$ para as mudas cultivadas nos solos sob MN2 e AGR, respectivamente (Figura 3b).

As maiores médias de matéria seca da parte aérea (MSPA), assim como verificado para o NN e a MFN, também foram obtidas nas mudas cultivadas nos solos de AGR e PAS, sendo significativamente superiores às obtidas nos solos sob MN1 e MN2 (Figura 4a). Correlação positiva moderada foi verificada entre a MSPA e o parâmetro $\mathrm{NN}(\mathrm{r}=0,62 ; \mathrm{p}<0,01)$ e forte com a MFN ( $\mathrm{r}=0,82 ; \mathrm{p}<0,01)$ (Tabela 3$)$.

Ao contrário do verificado para a MSPA, as mudas cultivadas nos solos de MN1 e MN2 apresentaram médias de matéria seca das raízes (MSR) significativamente superiores às obtidas nos solos de AGR e PAS (Figura 4B). Os menores valores da relação MSPA/MSR foram obtidos nas mudas cultivadas nos solos sob MN1 e MN2 (Figura 4d). Correlação negativa moderada e significativa $(r=-66 ; p<0,01)$ foi verificada entre a MSPA e MSR (Tabela 3).

O maior valor de matéria seca total (MST) foi verificado no solo de MN2. As mudas cultivadas nos solos de AGR e PAS apresentaram MST semelhantes entre si e superiores às mudas cultivadas no solo sob MN1 (Figura 4c). A MST correlacionou-se positivamente $(\mathrm{r}=$ 0,$67 ; \mathrm{p}<0,01$ ) com a MSR (Tabela 3).

As mudas cultivadas no solo de agricultura apresentaram acúmulo de nitrogênio na parte aérea (ANPA) superior às cultivadas nos demais solos. Os menores acúmulos foram obtidos nos solos sob MN1 e MN2, não havendo diferença entre si (Figura 4e). Verificou-se que o ANPA apresentou correlação positiva, moderada com o NN $(\mathrm{r}=0,46 ; \mathrm{p}<0,01)$ e alta com MFN $(\mathrm{r}=0,84 ; \mathrm{p}<0,01)$ (Tabela 3).

Os maiores valores do índice de qualidade de Dickson (IQD) foram obtidos nas mudas cultivadas nos solos de AGR, PAS e MN1, os quais foram semelhantes entre si (Figura 4f). 

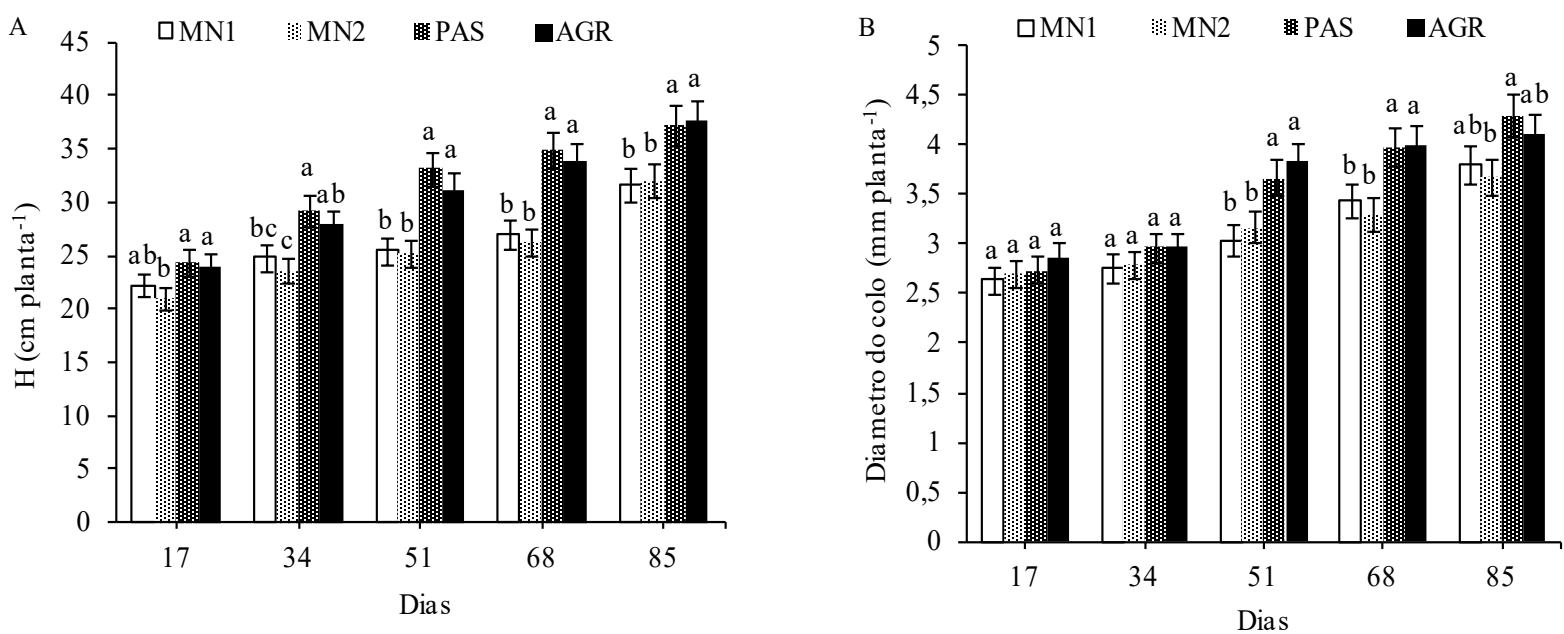

Figura 2. Valores médios da altura - H (A) e diâmetro do colo - DC (B) de mudas de tamboril, aos 17, 34, 51,68 e 85 dias após a semeadura, cultivadas em solos de diferentes sistemas de uso no Sudoeste do Piauí. Médias seguidas de mesma letra em cada época de avaliação não diferem entre si pelo teste de Tukey, a 5\% de probabilidade. MN1 = vegetação típica do bioma Caatinga, predominando arbustos ( 2 a $5 \mathrm{~m}$ ) que, em geral, perdem as folhas na estação seca; MN2 = vegetação de buritizal, onde predomina a palmeira Mauritia flexuosa L.; PAS = oito anos com plantio de pastagens (Brachiaria humudicola e Andropogon sp.) e rodízio de animais. AGR = vinte anos de rotação milho/feijão-caupi, sob plantio irrigado.
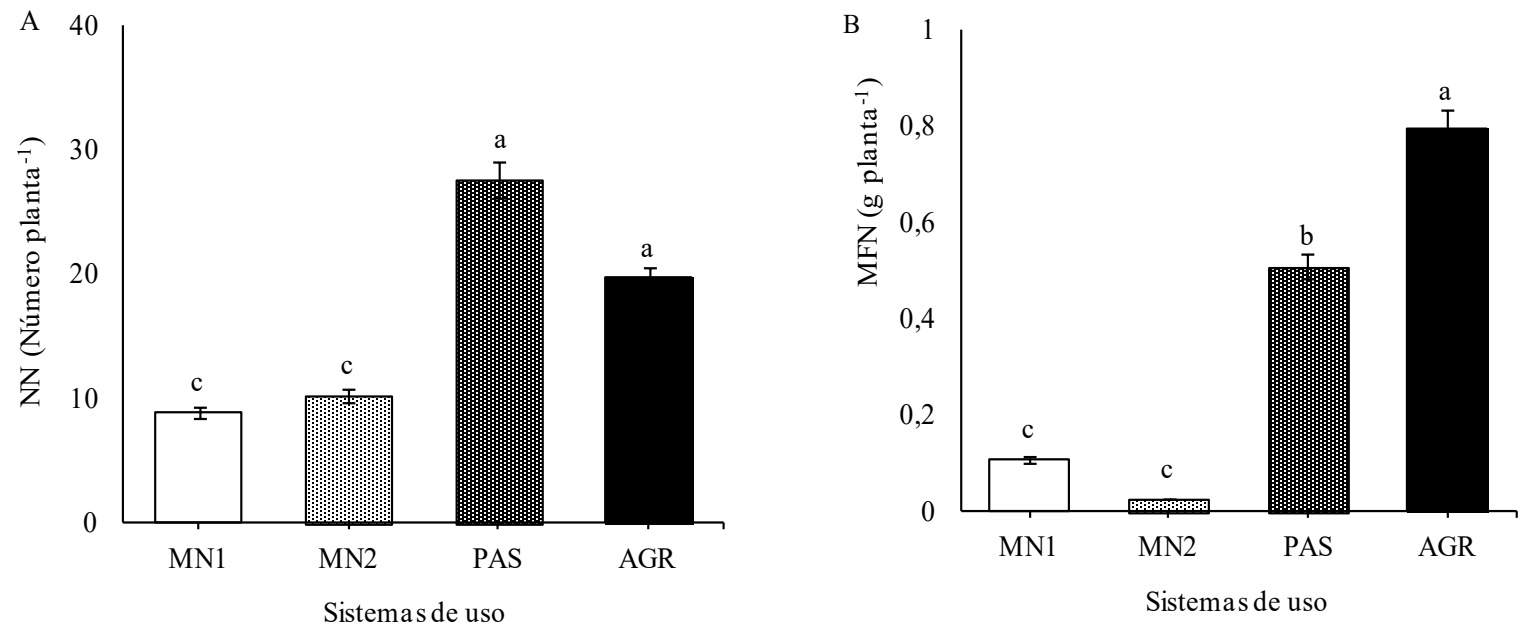

Figura 3. Número de nódulos - NN (A), matéria fresca de nódulos - MFN (B) de mudas de Enterolobium contortisiliquum (Vell) Morong. em solos de diferentes sistemas de uso no Sudoeste do Piaú, aos 85 dias após a semeadura. Médias com mesma letra não diferem entre si pelo teste de Tukey, a 5\% de probabilidade. MN1 = vegetação típica do bioma Caatinga, predominando arbustos ( 2 a $5 \mathrm{~m}$ ) que, em geral, perdem as folhas na estação seca; MN2 = vegetação de buritizal, onde predomina a palmeira Mauritia flexuosa L.; PAS $=$ oito anos com plantio de pastagens (Brachiaria humudicola e Andropogon sp.) e rodízio de animais. AGR = vinte anos de rotação milho/ feijão-caupi, sob plantio irrigado. 

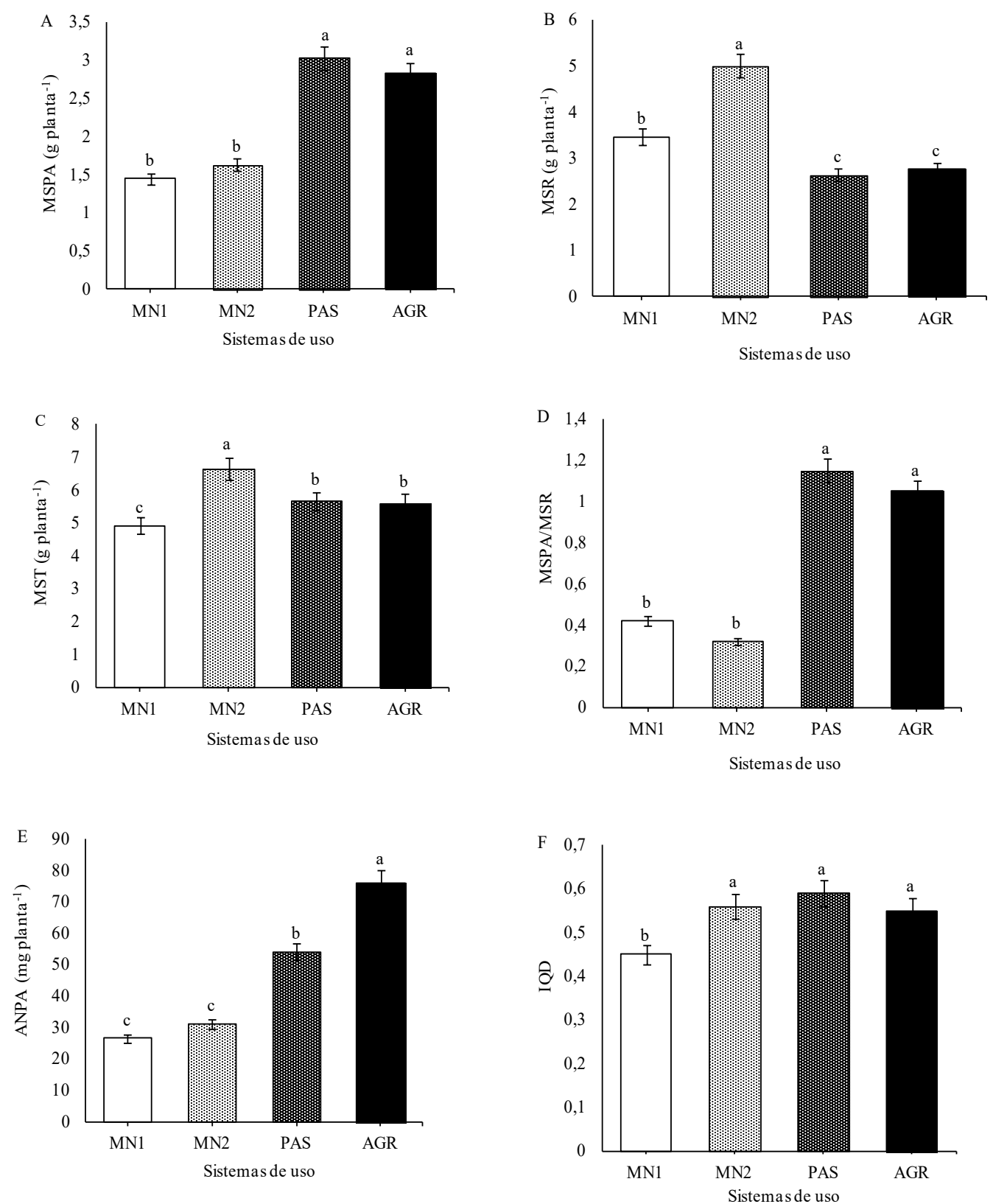

Figura 4. Matéria seca da parte aérea - MSPA (A), matéria seca das raízes - MSR (B), matéria seca total - MST (C), relação entre a matéria seca da parte aérea e das raízes - MSPA/MSR (D), acúmulo de nitrogênio na parte aérea - ANPA (E) e índice de qualidade de Dickson - IQD (F) de mudas de tamboril em solos de diferentes sistemas de uso no Sudoeste piauiense, aos 85 dias após a semeadura. MN1 = vegetação típica do bioma Caatinga, predominando arbustos (2 a $5 \mathrm{~m}$ ) que, em geral, perdem as folhas na estação seca; MN2 = vegetação de buritizal, onde predomina a palmeira Mauritia flexuosa L.; PAS = oito anos com plantio de pastagens (Brachiaria humudicola e Andropogon sp.) e rodízio de animais. AGR = vinte anos de rotação milho/feijão-caupi, sob plantio irrigado. 
Tabela 3. Coeficientes de correlação de Person entre o número de nódulos (NN), matéria fresca de nódulos (MFN), matéria seca da parte aérea (MSPA), matéria seca das raízes (MSR), matéria seca total (MST), relação entre a matéria seca da parte aérea e raízes (MSPA/MSR), acúmulo de nitrogênio na parte aérea (ANPA), altura (H), diâmetro do colo (DC) e índice de qualidade de Dickson (IQD) de mudas de tamboril aos 85 dias após a semeadura.

\begin{tabular}{|c|c|c|c|c|c|c|c|c|c|c|}
\hline & $\mathrm{NN}$ & MFN & MSPA & MSR & MST & $\begin{array}{l}\text { MSPA } \\
\text { /MSR }\end{array}$ & ANPA & $\mathrm{H}$ & D & IQD \\
\hline $\mathrm{NN}$ & - & $0,60^{* *}$ & $0,62^{* *}$ & $-0,54^{* *}$ & $-0,10^{\text {ns }}$ & $0,63^{* *}$ & $0,46^{* *}$ & $0,34^{*}$ & $0,19^{\text {ns }}$ & $0,27^{\text {ns }}$ \\
\hline MFN & & - & $0,82^{* *}$ & $-0,74^{* *}$ & $-0,17^{\mathrm{ns}}$ & $0,84^{* *}$ & $0,84^{* *}$ & $0,60^{* *}$ & $0,36^{*}$ & $0,31^{*}$ \\
\hline MSPA & & & - & $-0,66^{* *}$ & $0,11^{\mathrm{ns}}$ & $0,95^{* *}$ & $0,84^{* *}$ & $0,74^{* *}$ & $0,47^{* *}$ & $0,60^{* *}$ \\
\hline MSR & & & & - & $0,67^{* *}$ & $-0,83^{* *}$ & $-0,56^{* *}$ & $-0,46^{* *}$ & $-0,53^{* *}$ & $-0,08^{\mathrm{ns}}$ \\
\hline MST & & & & & - & $-0,16^{\mathrm{ns}}$ & $0,10^{\mathrm{ns}}$ & $0,12^{\mathrm{ns}}$ & $-0,23^{\mathrm{ns}}$ & $0,48^{* *}$ \\
\hline $\begin{array}{l}\text { MSPA/ } \\
\text { MSR }\end{array}$ & & & & & & - & $0,80^{* *}$ & $0,67^{* *}$ & $0,56^{* *}$ & $0,48^{* *}$ \\
\hline ANPA & & & & & & & - & $0,73^{* *}$ & $0,34^{*}$ & $0,40^{* *}$ \\
\hline $\mathrm{H}$ & & & & & & & & - & $0,38^{*}$ & $0,20^{\mathrm{ns}}$ \\
\hline $\mathrm{D}$ & & & & & & & & & - & $0,59^{* *}$ \\
\hline IQD & & & & & & & & & & - \\
\hline
\end{tabular}

\section{Discussão}

Os resultados obtidos nesse estudo em relação às variáveis altura $(\mathrm{H})$ e diâmetro do colo $(\mathrm{DC})$ indicam que o tamboril é uma espécie exigente em nutrientes na fase inicial do seu desenvolvimento, uma vez que as mudas apresentam rápida resposta em crescimento quando cultivadas em solos com melhores condições de fertilidade, em comparação àquelas cultivadas em solos com menor disponibilidade de nutrientes e maior saturação por alumínio, como no caso dos solos sob MN1 (mata nativa com vegetação típica do bioma Caatinga) e MN2 (mata nativa com vegetação de buritizal) (Tabela 2). Em outro estudo com mudas de tamboril, as plantas apresentaram menores médias de $\mathrm{H}$ e DC quando cultivadas com o substrato constituído por solo coletado na camada de 20 a $40 \mathrm{~cm}$, sem correção da acidez e sem adubação (Sousa et al., 2013). Os autores atribuíram o crescimento reduzido das mudas às condições menos férteis do substrato de cultivo e também à capacidade responsiva do tamboril à adição de nutrientes.

Souza et al. (2007), avaliando o desenvolvimento e a nodulação natural de leguminosas arbóreas em solos sob diferentes formas de uso, verificaram que o solo sob cobertura da leguminosa Calopogonium mucunoides, com as melhores condições de fertilidade, proporcionou maiores médias de $\mathrm{H}$ e DC de mudas de leucena em relação aos outros solos estudados, corroborando com os resultados do presente trabalho. Jesus et al. (2014) também obtiveram os maiores valores de $\mathrm{H}$ de mudas de tamboril quando cultivadas em solos com melhores condições de fertilidade.

A ocorrência de nodulação em todos os sistemas de uso do solo avaliados indica a ocorrência de populações nativas de bactérias fixadoras de nitrogênio nodulíferas capazes de estabelecerem simbiose com mudas de tamboril. A maior nodulação verificada nos solos de pastagem (PAS) e agricultura (AGR) pode estar relacionada ao tipo de cobertura vegetal e às melhores condições de fertilidade desses solos (Tabela 2). Mudanças na quantidade e qualidade de compostos exsudados liberados no solo, devido a mudanças na diversidade da cobertura vegetal, podem alterar a densidade, atividade e diversidade de bactérias diazotróficas (Dakora, 2003). A habilidade de nodulação das bactérias fixadoras de nitrogênio nodulíferas em leguminosas (BFNNL) é uma característica influenciada pela diversidade da cobertura vegetal (Lima et al., 2009; Jesus et al., 2014; Castro et al., 2017). Jesus et al. (2014) também verificaram, em estudo conduzido no Sudoeste do Piauí, relação direta entre a fertilidade do solo e nodulação em mudas de tamboril, sendo esta superior em solos de maior fertilidade. Resultados semelhantes foram reportados por Silva et al. (2009), em experimento com as leguminosas leucena, bordão-de-velho e feijão-caupi cultivadas em solos de Cerrado sob diferentes sistemas 
de uso. A baixa disponibilidade de alguns nutrientes, tais como Ca, Mg, P, Mo, Cu e Fe (Bonilla \& Bolanos, 2010; Moreira et al., 2010; Weisany et al., 2013) e a toxidez por Al (Arora et al., 2010; Mendoza-Soto et al., 2015) constituem fatores limitantes ao estabelecimento da simbiose entre leguminosas e rizóbio, com prejuízos para a nodulação e a fixação biológica de nitrogênio (FBN).

A maior produção de matéria seca da parte aérea (MSPA) e maior acúmulo de nitrogênio na parte aérea (ANPA) nos solos sob PAS e AGR podem ser atribuídos às melhores condições de fertilidade desses solos e às contribuições das populações nativas de bactérias fixadoras de nitrogênio que nodulam o tamboril e que, possivelmente, são mais abundantes nesses solos. Por outro lado, a maior produção de matéria seca das raízes (MSR) nos solos sob MN1 e MN2 em relação aos solos sob AGR e PAS era uma resposta esperada, pois dependendo da espécie vegetal, o crescimento radicular pode ser estimulado em solos de menor fertilidade (Marschner et al., 1991). Esse estímulo pode ser resultante de estratégias desenvolvidas pelas plantas para aumentar a aréa de exploração e absorção de nutrientes em condições de estresse nutricional (Marschner et al., 1991).

A relação MSPA/MSR é um importante índice morfológico relacionado ao padrão de qualidade das mudas. Quanto menor for o valor dessa relação, maior será o peso da massa radicular, podendo indicar maior resistência da muda em campo, devido à sua maior capacidade de absorção de água e nutrientes (Gomes et al., 2002). Os menores valores dessa relação obtidos nas mudas cultivadas nos solos sob MN1 e MN2, no presente trabalho, pode está relacionado ao fato do tamboril ter o seu crescimento radicular estimulado, como estratégia de sobrevivência, em solos com baixa fertilidade.

O índice de qualidade de Dickson (IQD), além de ser um bom índice de qualidade de mudas, é considerado uma promissora medida morfológica ponderada, pois considera, em sua fórmula, o vigor e o equilíbrio da distribuição da biomassa das plantas, ponderando várias características consideradas importantes (Melo et al., 2008). Os maiores valores de IQD, obtidos nas mudas cultivadas nos solos de AGR, PAS e MN1 indica que esses sistemas de uso do solo proporcionam o melhor padrão de qualidade das mudas de tamboril.

Entre todas as variáveis avaliadas no presente trabalho, destaca-se as correlações positivas entre matéria fresca de nódulos (MFN) e as variáveis MSPA, ANPA, DC,
H e IQD (Tabela 3). Essas correlações sugerem que as populações nativas de bactérias fixadoras de nitrogênio nodulíferas contribuem, de forma significativa, para o crescimento, nutrição e a qualidade das mudas de tamboril, corroborando estudos desenvolvidos recentemente em solos do Sudoeste do Piauí (Sousa et al., 2013; Jesus et al., 2014). Correlações positivas e significativas entre a nodulação e a produção de MSPA ou ANPA de mudas de espécies leguminosas arbóreas têm sido observadas em diversos estudos (Souza et al., 2007; Vieira \& Souza, 2011; Azad et al., 2013; Imane, 2015).

\section{Conclusões}

As mudas de tamboril [Enterolobium contortisiliquum (Vell) Morong.] apresentaram maior nodulação natural, crescimento e acúmulo de nitrogênio na parte aérea em solos oriundos de pastagem e agricultura do Sudeste do Piauí, Brasil.

As populações de bactérias fixadoras de nitrogênio nodulíferas nativas de solos do Sudoeste do Piauí apresentam potencial para serem isoladas e selecionadas para utilização como inoculantes na produção de mudas de tamboril.

\section{Referências}

Arora, N. K. et al. Effect of Al and heavy metals on enzymes of nitrogen metabolism of fast and slow growing rhizobia under explants conditions. World Jornal Microbiology Biotechnology, v. 26, n. 5, p. 811-816, 2010. DOI: 10.1007/s11274-009-0237-6.

Azad, M. S. et al. Functional relationships of nodulation response and biomass production at nursery stages of two fast-growing, leguminous-multipurpose tree species in Bangladesh: Albizia saman and Leucaena leucocephala. Forest Science and Practice, v. 15, n. 4, p. 274-285, 2013. DOI: 10.1007/s11632-013-0416-2.

Bonilla, I. \& Bolanos, L. Mineral nutrition for legume-rhizobia symbiosis: B, Ca, N, P, S, K, Fe, Mo, Co, and Ni: A review. Organic Farming, Pest Control and Remediation of Soil Pollutants, v. 1, p. 253-274, 2010. DOI: 10.1007/978-1-4020-9654-913.

Brasil. Ministério da Agricultura, Pecuária e Abastecimento. Instrução normativa ${ }^{0} 13$ de 24 de março de 2011. Disponível em: $<$ http://sistemasweb.agricultura.gov.br/sislegis/action/detalhaAto. do? method=recuperarTextoAtoTematicaPortal\& codigoTemati $\mathrm{ca}=1229256>$. Acesso em: 12 mar. 2014.

Castro, J. L. et al. Diversity and efficiency of rhizobia communities from iron mining areas using cowpea as a trap plant. Revista Brasileira de Ciência do Solo, v. 41, p. e0160525, 2017. DOI: $10.1590 / 18069657 \mathrm{rbcs} 20160525$. 
Chaer, G. M. et al. Nitrogen-fixing legume tree species for the reclamation of severely degraded lands in Brazil. Tree Physiology, v. 31, n. 2, p. 139-149, 2011. DOI: 10.1093/treephys/tpq116.

Claessen, M. E. C. (Org.). Manual de métodos de análise de solo. 2. ed. Rio de Janeiro: EMBRAPA-CNPS, 1997. 212 p. (EMBRAPACNPS. Documentos, 1).

Costa, E. M. et al. Resposta de duas cultivares de feijão-caupi à inoculação com bactérias fixadoras de nitrogênio em ambiente protegido. Revista Brasileira de Ciências Agrárias, v. 9, n. 4, p. 489-494, 2014. DOI: 10.5039/agraria.v9i4a3590.

Dakora, F. D. Defining new roles for plant and rhizobial molecules in sole and mixed plant cultures involving symbiotic legumes. New Phytologist, v. 158 , n. 01, p. 39-49, 2003. DOI: 10.1046/j.14698137.2003.00725.x.

Dickson, A. et al. Quality appraisal of white spruce and white pine seedling stock in nurseries. Forestry Chronicle, v. 36, n. 1, p. 10-13, 1960. DOI: $10.5558 / \mathrm{tfc} 36010-1$.

Ferreira, D. F. Sisvar: a computer statistical analysis system. Ciência e Agrotecnologia, v. 35, n. 6, p. 1039-1042, 2011. DOI: 10.1590/ S1413-70542011000600001.

Ferreira, L. V. M. et al. Crescimento e nodulação de Sesbania virgata com estirpes nativas e introduzidas. Revista de Ciências Agrárias, v. 58, n. 4, p. 327-334, 2015. DOI: 10.4322/rca.1881.

Gomes, J. M. et al. Parâmetros morfológicos na avaliação da qualidade de mudas de Eucalyptus grandis. Revista Árvore, v. 26, n. 6, p. 655-664, 2002. DOI: 10.1590/S0100-67622002000600002.

Imane, A. Symbiotic efficiency of Acacia cyanophylla lindl and Acacia pycnantha benth in four soil types. International Journal of Plant \& Soil Science, v. 6, n. 3, p. 116-123, 2015. DOI : 10.9734/ IJPSS/2015/15760.

Jaramillo, P. M. D. et al. Symbiotic nitrogen-fixing bacterial populations trapped from soils under agroforestry systems in the Western Amazon. Scientia Agricola, v. 70, n. 6, p. 397-404, 2013. DOI: $10.1590 / \mathrm{S} 0103-90162013000600004$.

Jesus, A. A. et al. Quality of Enterolobium contortisiliquum (Vell.) Morong. seedlings in function of inoculation and natural nodulation in soils from southwest of Piauí, Brazil. Revista de Ciências Agrárias, v. 37, n. 2, p. 198-205, 2014.

Lima, A. S. et al. Nitrogen-fixing bacteria communities occurring in soils under different uses in the Western Amazon Region as indicated by nodulation of siratro (Macroptilium atropurpureum). Plant and Soil, v. 319, n. 1, p. 127-145, 2009. DOI: 10.1007/ s11104-008-9855-2.
Lorenzi, H. Árvores brasileiras: manual de identificação e cultivo de plantas arbóreas nativas do Brasil. 5. ed. Nova Odessa: Instituto Plantarum, 2008. 384 p.

Marschner, H. Mechanisms of adaptation of plants to acid soils. Plant and Soil, v. 134, n. 1, p. 1-20, 1991. DOI: 10.1007/BF00010712.

Melo, R. R. et al. Crescimento inicial de mudas de Enterolobium contortisiliquum (Vell.) Morong. sob diferentes níveis de luminosidade. Revista Brasileira de Ciências Agrárias, v. 3, n. 2 , p. 138-144, 2008. DOI: 10.5039/agraria.v3i2a263.

Mendoza-Soto, A. B. et al. Responses of symbiotic nitrogen-fixing common bean to aluminum toxicity and delineation of nodule responsive microRNAs. Frontiers in Plant Science, v. 6, p. 587, 2015. DOI: $10.3389 /$ fpls.2015.00587.

Menezes, K. A. S. et al. Seedling development of nodulating and nonnodulating native legumes in soils from Brazilian Caatinga biome. Plant Science Today, v. 2, n. 2, p. 56-59, 2015. DOI: 10.14719/ pst.2015.2.2.97.

Moreira, F. M. S. et al. Effects of fertilizers, lime, and inoculation with rhizobia and mycorrhizal fungi on the growth of four leguminous tree species in low-fertility soil. Biology and Fertility Soils, v. 46, n. 8, p. 771-779, 2010. DOI: 10.1007/s00374-010-0477-5.

Novais, R. F. et al. (Ed.) Fertilidade do solo. Viçosa, MG: SBCS, 2007. 1017 p.

Rangel, W. M. et al. Phytoprotective effect of arbuscular mycorrhizal fungi species against arsenic toxicity in tropical leguminous species. International Journal of Phytoremediation, v. 16, p. 840-858, 2014. DOI: $10.1080 / 15226514.2013 .856852$.

Silva, E. F. L. et al. Nodulação natural de leguminosas em solos de cerrado do estado do Piauí. Revista Brasileira de Ciências Agrárias, v. 4, n. 3, p. 274-277, 2009. DOI: 10.5039/agraria.v4i3a7.

Sousa, W. C. et al. Fontes de nitrogênio e caule decomposto de Mauritia flexuosa na nodulação e crescimento de Enterolobium contortsiliquum. Revista Árvore, v. 37, n. 5, p. 969-979, 2013. DOI: 10.1590/S0100-67622013000500019.

Souza, L. A. G. et al. Desenvolvimento e nodulação natural de leguminosas arbóreas em solos de Pernambuco. Pesquisa Agropecuária Brasileira, v. 42, n. 2, p. 207-217, 2007. DOI: 10.1590/S0100-204X2007000200009.

Vieira, E. P. \& Souza, L. A. G. Inoculação com rizóbios em mudas de acapu do igapó e saboarana. Revista de Ciência Agrárias, v. 54, n. 1, p. 52-60, 2011. DOI: 10.4322/rca.2011.038.

Weisany, W. et al. Role of some of mineral nutrients in biological nitrogen fixation. Bulletin of Environment, Pharmacology and Life Sciences, v. 2, n. 4, p. 77-84, 2013. 
